\title{
Gender Inequality: A Vulnerability Factor To Hiv Infection Among Heterosexual Couples In Kenya
}

\author{
Mary Ingadoh Isalambah \\ Masinde Muliro University of Science and Technology \\ DOI: 10.29322/IJSRP.10.08.2020.p104105 \\ http://dx.doi.org/10.29322/IJSRP.10.08.2020.p104105
}

\begin{abstract}
Gender has been recognized as a major issue that is central to the spread of HIV and AIDs infection. Women are more vulnerable to HIV infection due to their biological susceptibility, limited sexual autonomy and men's power to control sexual activities. Gender- based social inequalities have been observed in which women lack the power to protect themselves from contracting HIV. Women are more susceptible to HIV infection through vaginal intercourse as they are exposed to infectious fluids longer during sexual intercourse than men. Pressure and Release Model, was used to drive this study. Mixed method research design was used to address the phenomenon under investigation. The study population comprised of 1180 heterosexual couples who were randomly selected and 73 key informants who were purposively selected. Primary data was collected using structured questionnaire and interview schedule. Descriptive and inferential data analysis were performed to derive meaning out of the collected data. The study established that gender inequality is a major factor influencing heterosexual couples' vulnerability to HIV infection in Kakamega County, Kenya. The study recommends need to intensify sensitization campaigns to boost couples' knowledge on HIV pandemic in order to reduce their vulnerability to HIV infection.
\end{abstract}

Key words: Gender inequality, heterosexual couples, HIV infection, vulnerability

\section{INTRODUCTION}

Gender has been recognized as a major issue that is central to the HIV and AIDs debate. It has been reported that Worldwide, 18.6 million girls and women were already infected with HIV besides the one million who were newly infected in 2015 (UNAIDS, 2017). In sub-Saharan Africa, women represent 59\% of new HIV infections among adults aged 15 years and older. Women are more vulnerable to HIV infection due to their biological susceptibility, limited sexual autonomy and men's power to control sexual activities (Wagbara, 2017). Women have therefore become the most vulnerable group of HIV infection. Moreover, gender- based social inequalities have been observed in which women lack the power to protect themselves from contracting HIV, and men are more likely than women to infect their partners because they engage in more risk sexual behaviours. In this case Higgins et al., (2010) noted that men are active transmitters of HIV but inactive agents of prevention.

Women have twice the chances of getting infection if they are exposed to HIV as compared to men (UNICEF, 2008). This happens because women are more susceptible to HIV infection through vaginal intercourse as they are exposed to infectious fluids longer during sexual intercourse than men are (Philbin, 2016). During sexual intercourse, the vagina sustains microscopic tears through which the virus enters the blood stream. Young girls are most vulnerable due to their immature mucosal epithelial linings which are even more easily torn during sexual intercourse (Huang, 20020. Moreover, increased vulnerability to HIV infection has been linked to intimate partner violence, which is commonly observed among younger women and women who are economically dependent on their male partners (Indicators, 2018).

Violence or the fear of violence can make it very hard for women to insist on safer sex and to use and benefit from HIV services (Mohammed et al., 2017). Siemieniuk et al., (2013) have confirmed that women infected with HIV who experienced intimate partner 
violence were less likely to begin or adhere to antiretroviral therapy than other HIV infected women. Besides, violence against women contributes to women's vulnerability to HIV through fear to negotiate for safer sex (Gupta, 2000) and for those who are raped; the genital tears they sustain increase their probability of being infected with HIV (Qubuda, 2010).

\section{LITERATURE REVIEW}

In Africa women are more affected by HIV and AIDS. This is because in African cultures, women occupy an inferior position both socially and economically and find themselves acquiescing to men's risky sexual behaviour such as multiple sexual partners and not using condoms (ILO/AIDS, 2002). Gender inequality, HIV risks and vulnerabilities are inextricably linked. Women account for just over 50 per cent of all people living with HIV (UNAIDS, 2013).

Societal gender norms related to "feminine" and "masculine" roles, expectations and behaviours strongly affect women's and men's access to HIV information and services, their attitudes and sexual behaviour, and how they cope with the situation, should they or a family member be living with HIV (UNAIDS, 2011). Of the 33.3 million people globally living with HIV in 2009, 15.9 million were women (UNAIDS, 2010). In 2017, an estimated 18.2 million women were living with HIV, constituting 52\% of all adults living with HIV, besides, an estimated 1.6 million new HIV infections in adults globally were among women (UNAIDS, 2017).

In East and Southern Africa 19.6 million people were living with HIV in 2017 of this more than half were women and girls (UNAIDS, 2017). However, infection rates among women are rising in several countries, as transmission patterns shift from high-risk groups to the general population where increasing numbers of vulnerable women and girls are becoming infected.

In Kenya women are among the groups mostly affected by HIV/AIDs. Statistics show that in 2016, women accounted for 910,000 of the 1.6 million people living with HIV in Kenya (NACC, 2016). The main reason is that women in Kenya are discriminated against in terms of access to education, employment and healthcare. As a result, men often dominate sexual relationships, with women being unable to practice safer sex even when they know the risks. Women and girls are more affected by the burden of caring for family members who are sick, which increases their unpaid workload while diminishing their access to schooling or income-generating activities (UNAIDS, 2011).

It is therefore against this background that this research sought to find out whether gender inequality is a factor of vulnerability to HIV infection among heterosexual couples in Kakamega County.

\section{RESEARCH METHODOLOGY}

Research design is a reflection upon a researcher's ideas with a focus on binding the research together through a blueprint that shows how the different parts of the research will work in unison so as to address the research questions (Asenahabi, Busula, \& Ronoh, 2019). Mixed method research design was adopted to enable the researcher gather data, opinions and views about gender inequality as a vulnerability factor of HIV infection among heterosexual couples in Kenya. Mixed method research design will enable the researcher collect both qualitative and quantitative data. Under mixed method research design, qualitative research brings in openended data without predetermined responses while quantitative research brings in closed-ended data (Asenahabi, 2019). Triangulation design was used to integrate complimentary yet distinctly different data about gender inequality as a vulnerability factor for HIV infection among heterosexual couples. 
The study population was heterosexual couples because HIV infection is best characterized as a sexually transmitted disease. Globally, more than $90 \%$ of new HIV infection among adults are acquired through sexual activity (Gouiws et al., 2006), and heterosexual contact accounts for $80 \%$ of new cases of HIV in women (CDC, 2006). The units of analysis constituted of heterosexual couples, CASCO, SCASCOs, CACCs, HTC and CCC counsellors, Chiefs, Assistant Chiefs and Village elders in the area of study. A household in this research is represented by a heterosexual couple, and for every heterosexual couple only one member responded to the questionnaire.

A sample size of one thousand one hundred and eighty (1180) heterosexual couple respondents were randomly selected to take part in the study. Primary data was collected using a questionnaire for quantitative data and interviews for qualitative data. Questionnaires were used to get information about current conditions and practices and to make enquiries concerning attitude and opinion quickly and in a precise manner (Singh, 2006). An interview schedule, structured according to the research objective variables was used to collect raw data from the key informants who included the CASCO, SCASCOs, CACCs, HTC Counselors, Chiefs, Assistant Chiefs and Village elders.

Quality of the data collection instruments was ensured using both validity and reliability. The validity of the instrument is asking the right question framed in the least ambiguous way (Best \& Khan, 2005). To ensure that the instruments have the content validity, they were submitted to experts for subjective judgment. To ensure items in the questionnaire and interview schedule are reliable, a pilot study was conducted. The reliability of the questionnaire was then checked by calculating the internal consistency using Cronbach's alpha coefficient to determine the extent to which the items that make up the scale are all measuring the same underlying attribute. The internal consistency reliability for the scale had a Cronbach alpha coefficient value of 0.746.

Qualitative data was analyzed and represented in text form. Quantitative data was analyzed using both descriptive and inferential data analysis.

\section{FINDINGS}

\section{A. Gender of respondents}

The heterosexual couple respondents were asked to indicate their gender and the results were as shown in Figure 1.

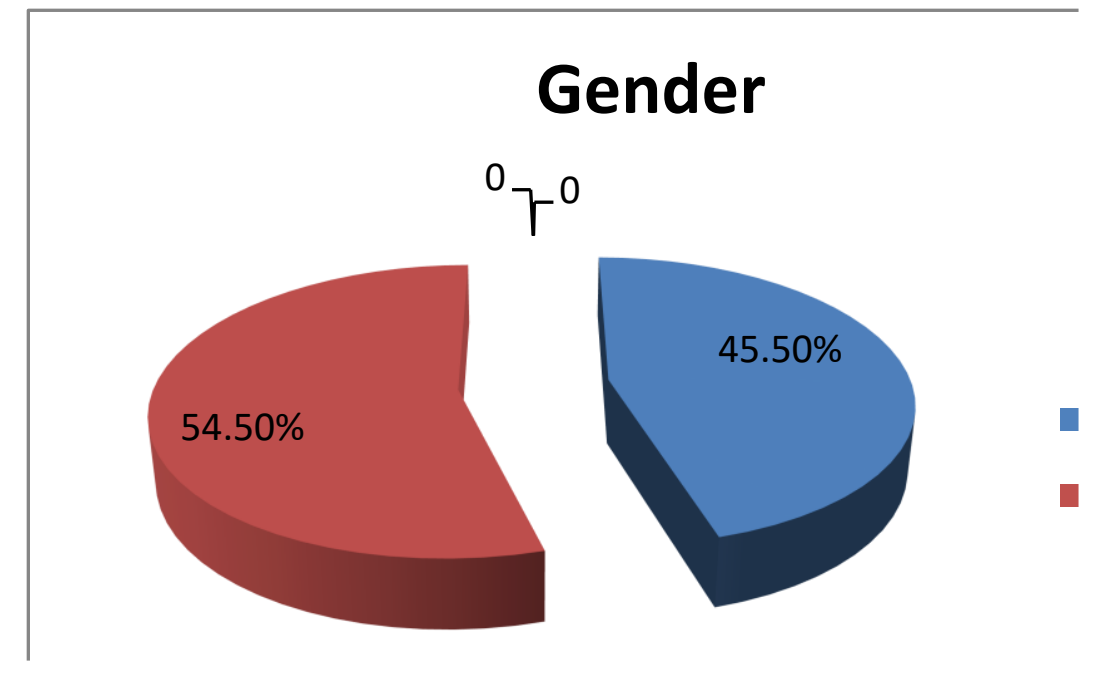


A total of 1180 heterosexual couple respondents participated in the study. Of this population, 537 (45.5\%) were males while 643 $(54.5 \%)$ were females. The number of females who participated in the study was slightly higher than that of males.

\section{B. Age Distribution of the Respondents}

The target population of this study was heterosexual couples aged between 15 and 64 years. The respondents were asked to indicate their age and their results were as shown in Figure 2

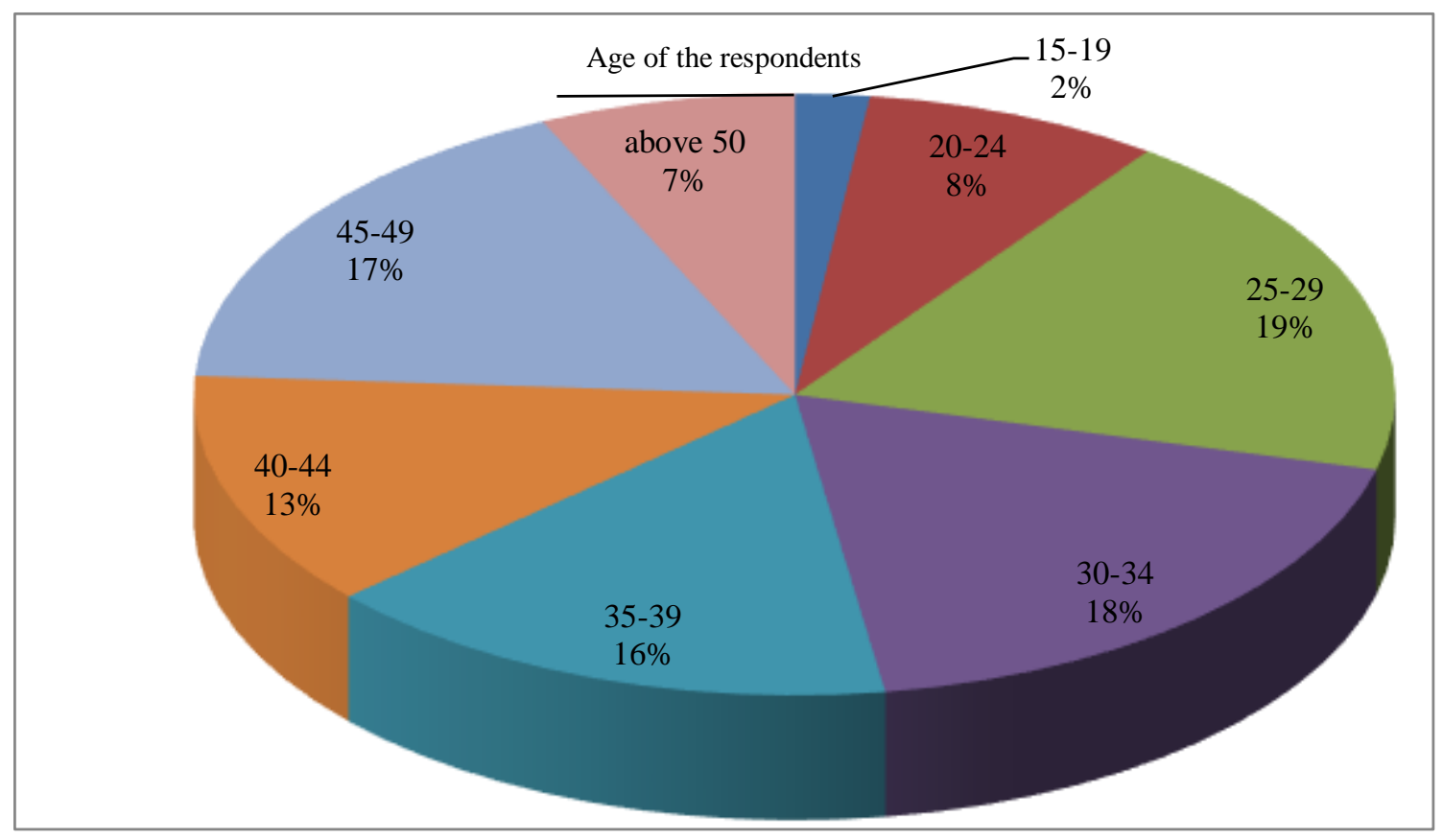

Figure 2: Proportion of respondents by age

Figure 2 represents the age proportion of the respondents who participated in the study. Heterosexual couples in the age bracket of 15 to 19 years were least represented with a proportion of $2 \%$. This was followed by those who are above 50 years by a proportion of $7 \%$. There is almost an equal distribution of heterosexual couples in the age bracket between 25 and 49 years.

\section{Level of Education among the Respondents}

Level of education was among the socio demographic characteristics considered for the heterosexual couple respondents. The heterosexual couple respondents were asked to indicate the highest level of education that they have attained.

The level of education varied from those who have no formal education to primary and secondary education, college or university education as shown in Figure 3. 


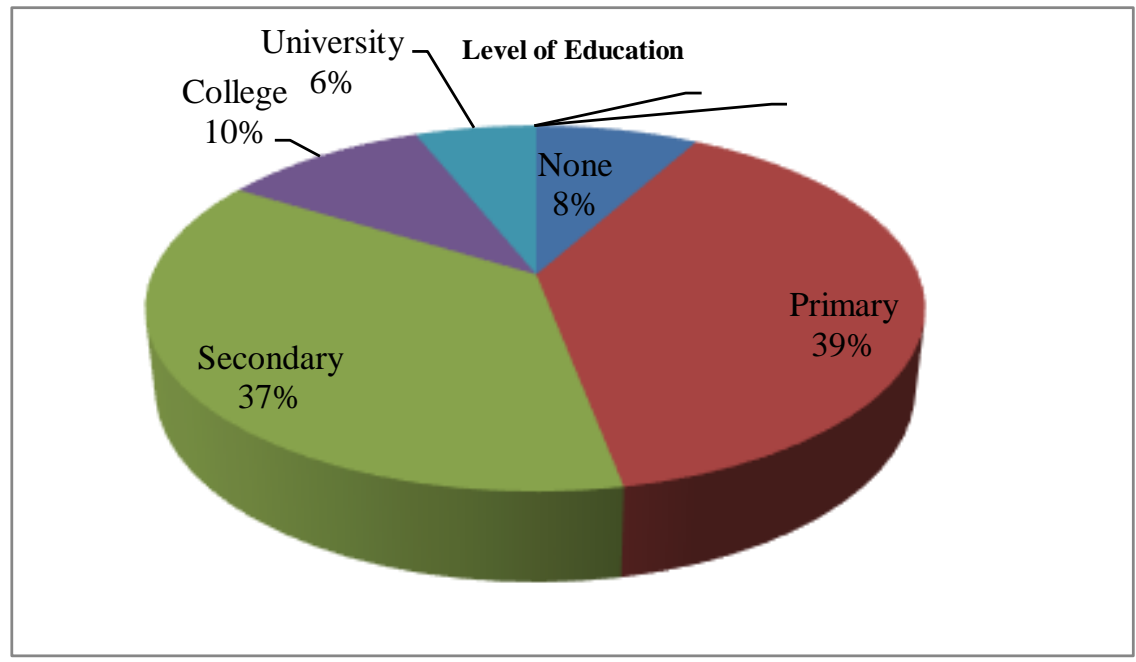

\section{Figure 3: Level of Education among respondents}

Of the 1180 heterosexual couple respondents who participated in the study $95(8.1 \%)$ had no formal education, $461(39.1 \%)$ had primary education, $433(36.7 \%)$ had secondary education, $120(10.1 \%)$ had gone to college and $71(6.0 \%)$ had attained university education. The lowest proportion was among couple respondents with university education and the highest proportion was among those with primary education. The proportion of heterosexual couples who have primary $(39.1 \%)$ and secondary $(36.7 \%)$ education is highest and the gap between them seems to be narrow.

This result is in agreement with the report in "Kenya Economic Updates" (World Bank, 2013), that Kenya has made significant gains in making Basic Education accessible broadly, Basic Education in this case includes both primary and secondary education. The introduction of free and universal primary education, the increase in the number of secondary- day schools and the support the government gives to schools and learners in form of tuition and learning materials have played a significant role in this gain.

The proportion of heterosexual couple respondents who had gone to university $71(6.0 \%)$ and other tertiary colleges $120(10.1 \%)$ is still low. This may be due to the sieving done by examinations at the end of secondary education and the high economic requirements at the higher levels of learning. The proportion of heterosexual couple respondents who had no formal education was low 95 (8.1\%), this result is in agreement with the Kenya Economic Update report that primary enrolment rates in Kenya are now almost universal (World Bank, 2013) due to the introduction of free and universal education.

\section{Gender norms as a vulnerability}

To determine what the society expects of men and women in relation to feminine and masculine roles, expectations and behaviour that would affect women's and men's access to HIV information and services, their attitude and sexual behaviour, heterosexual couples were asked questions relating to the involvement of male or female partners of a couple in decision making on sexual matters.

Regarding decision making, the heterosexual couples were asked who decides on the number of children to have in a couple. Their responses were as shown in Table 1. 
Table 1: Decision maker on how many children to have and when to have them

\begin{tabular}{|c|c|c|c|c|c|c|c|}
\hline & & & \multicolumn{4}{|c|}{$\begin{array}{l}\text { How many children to have and when to have } \\
\text { them }\end{array}$} & \multirow[t]{2}{*}{ Total } \\
\hline & & & Husband & Wife & Both & Depends & \\
\hline \multirow[t]{6}{*}{ Gender } & Male & Count & 390 & 12 & 106 & 29 & 537 \\
\hline & & $\begin{array}{l}\% \text { within How many } \\
\text { children to have and } \\
\text { when to have them }\end{array}$ & $45.5 \%$ & $24.0 \%$ & $51.5 \%$ & $43.3 \%$ & $45.5 \%$ \\
\hline & & $\%$ of Total & $33.1 \%$ & $1.0 \%$ & $9.0 \%$ & $2.5 \%$ & $45.5 \%$ \\
\hline & Female & Count & 467 & 38 & 100 & 38 & 643 \\
\hline & & $\begin{array}{l}\% \text { within How many } \\
\text { children to have and } \\
\text { when to have them }\end{array}$ & $54.5 \%$ & $76.0 \%$ & $48.5 \%$ & $56.7 \%$ & $54.5 \%$ \\
\hline & & $\%$ of Total & $39.6 \%$ & $3.2 \%$ & $8.5 \%$ & $3.2 \%$ & $54.5 \%$ \\
\hline \multirow[t]{2}{*}{ Total } & & Count & 857 & 50 & 206 & 67 & 1180 \\
\hline & & $\%$ of Total & $72.6 \%$ & $4.2 \%$ & $17.5 \%$ & $5.7 \%$ & $100.0 \%$ \\
\hline
\end{tabular}

The findings in Table 1 indicate that it is the husband who has the greatest say when deciding on the number of children to have and when to have them with (857) $72.6 \%$ followed by the couple with (206) $17.5 \%$ and lastly the wife with only (50) $4.2 \%$. Of the (857) $72.6 \%$ respondents who say the husband is the decision maker, (390) $33.1 \%$ are males and (467) 39.6\% are females. Of the (50) $4.2 \%$ who say the wife is the decision maker (12) $1.0 \%$ are males and (38) $3.2 \%$ are females. Both the male and the female respondents agree that it is the husband who makes the decision with (857) $72.6 \%$ responses.

These findings confirm that the wife has minimal chance of making decision in child bearing yet biologically the woman can control child bearing given her knowledge of her menstrual cycle. The respondents were also asked who decides on when to have sexual intercourse in a couple. The responses to the question who decides on when to have sexual intercourse in a couple were shown in Table 2.

Table 2: Who decides on when to have sexual intercourse?

\begin{tabular}{|c|c|c|c|c|c|c|c|c|}
\hline & & & & \multicolumn{4}{|c|}{ When to have sexual intercourse } & \multirow[t]{2}{*}{ Total } \\
\hline & & & & Husband & Wife & Both & Depends & \\
\hline \multirow[t]{7}{*}{ Gender } & Male & Count & & 303 & 3 & 103 & 128 & 537 \\
\hline & & $\%$ within & When to & $44.8 \%$ & $8.3 \%$ & $47.5 \%$ & $51.0 \%$ & $45.5 \%$ \\
\hline & & have & sexual & & & & & \\
\hline & & intercourse & & & & & & \\
\hline & & $\%$ of Total & & $25.7 \%$ & $.3 \%$ & $8.7 \%$ & $10.8 \%$ & $45.5 \%$ \\
\hline & Female & Count & & 373 & 33 & 114 & 123 & 643 \\
\hline & & $\%$ within & When to & $55.2 \%$ & $91.7 \%$ & $52.5 \%$ & $49.0 \%$ & $54.5 \%$ \\
\hline
\end{tabular}




\begin{tabular}{|c|c|c|c|c|c|c|c|}
\hline & have & sexual & & & & & \\
\hline & $\%$ of Total & & $31.6 \%$ & $2.8 \%$ & $9.7 \%$ & $10.4 \%$ & $54.5 \%$ \\
\hline \multirow[t]{5}{*}{ Total } & Count & & 676 & 36 & 217 & 251 & 1180 \\
\hline & $\%$ within & When to & $100.0 \%$ & $100.0 \%$ & $100.0 \%$ & $100.0 \%$ & $100.0 \%$ \\
\hline & have & sexual & & & & & \\
\hline & intercourse & & & & & & \\
\hline & $\%$ of Total & & $57.3 \%$ & $3.1 \%$ & $18.4 \%$ & $21.3 \%$ & $100.0 \%$ \\
\hline
\end{tabular}

The findings in Table 2 show that it is the husband who has the greatest say on when to have sexual intercourse with (676) 57.3\%, followed by the couple with (217) $18.4 \%$ and lastly the wife with (36) $3.1 \%$.

Of the (676) $57.3 \%$ respondents who say the husband is the decision maker, (303) $25.7 \%$ are males and (373) $31.6 \%$ are females. Of the (36) $3.1 \%$ who say the wife is the decision maker (3) $0.3 \%$ are males and (33) $2.8 \%$ are females.

Both the male and the female respondents agree that it is the husband who makes the decision on when to have sexual intercourse with (676) $57.3 \%$ of the responses. These findings confirm that the husband is the decision maker on matters of sexual intercourse. Besides, the respondents were asked who decides on when to have safer sex in a couple. Table 3 shows the results when respondents were asked who decides on when to have safer sex in a couple.

Table 3: Who decides on when to have safer sex?

\begin{tabular}{|c|c|c|c|c|c|c|c|}
\hline & & & Husband & Wife & Both & Depends & Total \\
\hline \multirow[t]{6}{*}{ Gender } & Male & Count & 354 & 24 & 81 & 78 & 537 \\
\hline & & $\begin{array}{l}\% \text { within when to have } \\
\text { safer sex }\end{array}$ & $43.9 \%$ & $49.0 \%$ & $42.2 \%$ & $59.1 \%$ & $45.5 \%$ \\
\hline & & $\%$ of Total & $30.0 \%$ & $2.0 \%$ & $6.9 \%$ & $6.6 \%$ & $45.5 \%$ \\
\hline & Female & Count & 453 & 25 & 111 & 54 & 643 \\
\hline & & $\begin{array}{l}\% \text { within when to have } \\
\text { safer sex }\end{array}$ & $56.1 \%$ & $51.0 \%$ & $57.8 \%$ & $40.9 \%$ & $54.5 \%$ \\
\hline & & $\%$ of Total & $38.4 \%$ & $2.1 \%$ & $9.4 \%$ & $4.6 \%$ & $54.5 \%$ \\
\hline \multirow[t]{3}{*}{ Total } & & Count & 807 & 49 & 192 & 132 & 1180 \\
\hline & & $\begin{array}{l}\% \text { within when to have } \\
\text { safer sex }\end{array}$ & $100.0 \%$ & $100.0 \%$ & $100.0 \%$ & $100.0 \%$ & $100.0 \%$ \\
\hline & & $\%$ of Total & $68.4 \%$ & $4.1 \%$ & $16.3 \%$ & $11.2 \%$ & $100.0 \%$ \\
\hline
\end{tabular}

Sexual intercourse is said to be safer when a condom is used correctly and consistently. When asked who has the greatest say when to have safer sex, (48) $4.1 \%$ of the respondents said it is the wife, (807) $68.4 \%$ said it is the husband and (192) $16.3 \%$ said it is the couple. 
Of those who say husband is the decision maker, (454) $30 \%$ are males and (453) $38 \%$ are females. When the female is the decision maker (24) $2.0 \%$ males and (25) $2.1 \%$ females are the supporters.

The findings from the study therefore show that gender equality has an impact on decision making in a couple. This was in agreement with (WHO, 2009) who cited that gender inequalities arise hindering access to treatment. Walden, (2007) also found out that in Africa due to cultural traditions and beliefs women are found to be more vulnerable to HIV infection than men, citing situation where women are culturally obliged to have sex with little option to saying no.

A Key informant had the following comments on who should have the greatest say on deciding how many children to have, when to have sexual intercourse and when to have safer sex.

It could be necessary for both partners to discuss and come up with a decision as a couple as matters touching on sexual intercourse concern the couple as a unit. Both husband and wife could equally be involved in making decisions concerning HIV infection and prevention such as condom use, family planning and being faithful to one uninfected partner. These can be discussed during couple HIV Counselling and Testing (Source: field data, 2018).

The findings from current research show that it is the husband who is the decision maker on sexual activities that can lead to HIV infection and prevention thus it is a husband who is the decision maker of the household. The findings also depict gender inequality which is in agreement with the report from (Mwaura, 2009) that a larger population of Kenya (52\%) are women and they play an active role in the development of the society though their lives are marred by inequalities and inequities in many aspects of their life.

Naturally, women are biologically and physiologically more vulnerable to HIV infections than men (Scaccabarrozzi, 2008), women also face a number of social, economic and legal disadvantages that seriously limit their ability to protect themselves against HIV infection. According NACC (2005), women economic dependence on men makes them most vulnerable to HIV infection. This limits women's ability not only to access HIV prevention services and commodities but also diminishes their decision making power.

Research has shown that most married men in Kenya have extra marital sexual relationships and women rarely have the power to go against that practice. To realize any impact, women need to be more empowered economically in order to reduce their dependence on men. Women need to be more empowered educationally as lower levels of education lead to early marriage, more years in marriage and longer years of exposure to HIV. Comparatively, higher education levels for girls is associated with a higher age of marriage, higher economic power, improved health seeking behaviour, and reduced risk of HIV infection (Grown, et al., 2005).

Women could therefore be actively involved in decision making on matters pertaining to sexual intercourse and thus planning and implementing the action plan to protect the couple from HIV infection.

\section{CONCLUSION}

Gender inequality is clear with the husband being responsible for most decision making in the household 


\section{RECOMMENDATION}

1. Steps should be taken to reduce the vulnerability of married women and men to HIV infection. This could include stronger policies, better prevention strategies, and changes in harmful social norms.

2. Heterosexual couples should be re-educated about societal norms which negatively impact their health. This can assist to reduce HIV infection in marriages.

\section{REFERENCES}

Adimora, A. A., Schoenbach V J, and Daherty I. (2006). HIV and African Americans in the southern United States: sexual networks and social context. Sex Transm Dis, 33, S39-S45.

Asenahabi, B. M. (2019). Basics of Research Design: A Guide to selecting appropriate research design. International Journal of Contemporary Applied Researches, 6(5), 76 - 89.

Asenahabi, B. M., Busula, A. O., and Ronoh, R. (2019). A choice dilemma in selecting appropriate research design. International Journal of Advanced Research in Computer Engineering \& Technology (IJARCET), 8(8), 348 - 356.

Best, J.W. and Khan J.R. (2005). Research in Education (7 ${ }^{\text {th }}$ Edition) New Delhi Prentice.

Carter, M., Kraft, J. M, and Toppenhavaver, K. (2007). A bull is not meant to remain in the kraal: concurrent sexual relationships in Botswana. AIDS Behaviour.

CDC. (2006). HIV/AIDS Surveillance Report. CDC.

Choi, K. H., Gibson, D. R., Han, L., and Y. Guo. (2004). High Levels of Unprotected Sex with Men and Women: A Potentia Bridge of HIV Transmissionin Beijing. AIDS Educ Prev.

Gouiws, E. W., White, P. J., Stover, J and T., Brown. (2006). Short term estimates of adult HIV incidence by mode S. Sex Transm Infect, 82(3), 51-5.

Green, E., Mah, T., and Ruark, A. (2009). Framework of sexual partnerships: risks and implications for HIV prevention in Africa. Studies in Family Planning, 1(40), 63-70.

Gupta, G. (2000). Gender, Sexuality and HIV/AIDS: The What, the Why, and the How. Plenary Adress. XIIIth International Conference. Retrieved fromwww.icrw.org/docs/Durban-speed700.pdf.

Higgins J. A, Hoffman. S., and Dworkin, S. L. (2010). Rethinking gender, heterosexual men, and women's vulnerability to HIV/ AIDS. American Journal of Public Health, 100(3), 435-445.

Hilary, H. (2013). Uganda's Soaring HIV Infection Rate Linked to Infidelity. voanews.com.

Huang, M. (2002). HIV/AIDS among fishers: Vulnerability of their partners. In Williama, M. J; HIV/ AIDS among fishers: Vulnerabi . In H. M. Taaiwan, Penang: World Fish Centre.

ILO/AIDS. (2002). Implementing the ILO Code of Practice on HIV/AIDS and the world of work: an education and training manual Module \%. Retrieved from http://www.ilo.org/public/english/protection/trav/aids/publ/manual.htm.

Indicators, S. (2018, June 29). global database beta 0.2.45 In: unstats.un.org. Retrieved June 29,

2018, from https://unstats,un.org/sdgs/indicators/database/.

KAIS. (2012). National AIDS and STI Control Program. Nairobi: Ministry of Health.

Kalichman, S. C, Cain, D. (2007). ART information. Sex Transmission Infection, 83(5), 371-

375.

KDHS. (2014). Central Bureau of Statistics (CBS) (Kenya). Nairobi: Ministry of

Health.

Lagarde, E., Auvert. B., and Careael. (2001). Concurrent partnerships and HIV prevalence in five urban communities of Sub- Saharan Africa. AIDS, 15, 877-84.

This publication is licensed under Creative Commons Attribution CC BY.

http://dx.doi.org/10.29322/IJSRP.10.08.2020.p104105

www.ijsrp.org 
Mishra, V., Rathavuth, H. Bignam-Van, J. A., Barrere, B.. (2009). The ROle of Partner Reduction and Faithfulness in HIV Prevetnion in Sub-Saharan Africa: Evidence from Cameroon, Rwanda, Uganda, and Zimbabwe. DHS Working Papers No. 61. Calverton, Maryland: Macro International Inc.

Mohammed, B. H., Johnston, J. M., and Harwell, J. A. (2017). Intimate partner violence and utilization of maternal health care services. BMC Health Serv Res, 17(1), 178.

Mwaura, E. (2009). HIV/AIDS Prevention Strategies in Kenya: A critical Review. Pittsburgh: University of Pittsburgh.

NACC. (2005). Kenya national HIV/ AIDS strategic plan 2005/6-2009/10: a call to action. Nairobi: NACC, Office of the President.

NACC. (2016). Kenya HIV County Profiles. Nairobi: Ministry of Health.

NASCOP. (2012). National AIDS and STI Control Programme. Annual Report. . Nairobi:

Ministry of Health.

Noar, S. (2008). Behavioural interventions to reduce HIV-related sexual risk behaviour: review and synthesis of meta-analytic evidence. AIDS and Behaviour, 12(3), 1090.

Philbin, M. M. (2016). "What I got to go through". Normalization and HIV- positive adolescents.

J. Med. Anthropology, 33(4), 288- 302.

Qubuda, T. (2010). The Role of Culture in the HIV/AIDS Epidemic and Understanding and Addressing HIV-related Stigma. Unpublished class notes (Postgraduate Diploma in HIV and AIDS Management). University of Stellenbosch.

Sally, M. M., Pfeiffer, C., Geubbel, E. (2015). Prevalence and Social drivers of HIV among married and cohabiting heterosexual adults in South- eastern Tanzania: analysis of adult health community cohort data. Global Health Action, 8.

Scaccabarrozzi, L. (2008). HIV and women around the world:AIDS community research

Initiative of America. Retrieved Feb 2009, from http://www.thebody.com/content/art45489.html.

Shelton, J. D. (2009). Why multiple sex partners? The Lancet, 374, 367-369.

Siemieniuk, R. A., Krentz. H. B., Miller, P., Woodman, K. and Gill, M. J. (2013). The clinical implications of high rates Intimate partner violence HIV - positive women. $J$ Acquir Immune Defic Syndr, 64, 32-8.

Singh, K. (2006). Fundamental of Research Methodology and Statistics. New Delhi, India: New Age International Publishers.

UNAIDS. (2005). AIDS epidemic update. World Health Organization.

UNAIDS. (2011). 'Kenya to adopt comprehensive HIV prevention package for people who inject drugs .

UNAIDS. (2013). Kenya HIV Prevention Revolution Roadmap: Count Down to 2030. Nairobi:

Ministry of Health.

UNAIDS. (2017). when-women-lead-change-happens . Retrieved May 3, 2018, from

siteshttp://www.unaids.org/sites/default/files/media asset.

UNICEF. (2008). Retrieved May 3, 2018, from http://www.

Wagbara, M. (2017). Gender inequality in women's knowledge and awareness of HIV/ AIDS in

Port Harcourt. Doctoral Dissertation. Walden University, Port Harcourt.

WHO. (2009). Rapid advice: antiretroviral therapy for HIV infection in adults and adolescents. Retrieved fromhttp://www.who.int//hiv/pub/arv/rapid advice art.pdf

Author : Mary Ingadoh Isalambah, Email: masenahabi@yahoo.com 